Meta

Journal des traducteurs

Translators' Journal

\title{
Terminologie de la thérapie génique
}

\section{Marie Bitar}

Volume 46, numéro 1, mars 2001

Traduction médicale et documentation / Medical translation and documentation

URI : https://id.erudit.org/iderudit/002086ar

DOI : https://doi.org/10.7202/002086ar

Aller au sommaire du numéro

Éditeur(s)

Les Presses de l'Université de Montréal

ISSN

0026-0452 (imprimé)

1492-1421 (numérique)

Découvrir la revue

Citer ce document

Bitar, M. (2001). Terminologie de la thérapie génique. Meta, 46(1), 183-191.

https://doi.org/10.7202/002086ar

Ce document est protégé par la loi sur le droit d'auteur. L'utilisation des services d'Érudit (y compris la reproduction) est assujettie à sa politique d'utilisation que vous pouvez consulter en ligne.

https://apropos.erudit.org/fr/usagers/politique-dutilisation/ 


\title{
Terminologie de la thérapie génique
}

\author{
MARIE BITAR \\ Université de Montréal, Montréal, Canada
}

En raison de l'irrésistible ascension des biotechnologies et des progrès incommensurables du génie génétique, chaque année, des dizaines de nouvelles notions voient le jour et des centaines de nouveaux termes font leur entrée dans l'usage technicoscientifique et médical. Cependant, comme «abondance de biens nuit», la prolifération de ces nouvelles notions ne fait pas toujours le bonheur des terminologues et des traducteurs, dont la mission consiste à trouver les termes qui correspondent exactement aux notions évoquées (en situation unilingue) ainsi que les équivalents adéquats aux nouvelles entrées dans l'usage (en situation bilingue). Dans le but d'apporter une petite contribution à la terminologie biomédicale, le présent glossaire tente de recenser le lexique propre au domaine de la thérapie génique, nouvel axe thérapeutique du génie génétique. Les termes étudiés concernent les principales techniques thérapeutiques inspirées des manipulations du génie génétique et le vocabulaire de base spécifique à de telles applications.

Avant d'entamer l'étude terminologique du domaine de la thérapie génique, il serait important de définir cette notion-clé: la thérapie génique consiste à corriger les défauts de fonctionnement de l'organisme dus aux altérations des gènes, ces fragments du patrimoine génétique qui gouvernent la synthèse des protéines. Théoriquement, la thérapie génique peut revêtir plusieurs formes dont l'addition génique, la modification génique in situ et le remplacement génique. Cependant, dans les applications médicales actuelles du génie génétique, seule l'addition de gènes est praticable. C'est, d'ailleurs, la seule forme de thérapie génique que nous aborderons dans ce glossaire.

Au début des années 1980, la thérapie génique apparaissait comme une perspective lointaine et quasi inaccessible. Aujourd'hui, même si son efficacité reste à prouver et si ses conséquences éthiques et juridiques doivent être évaluées, les expériences menées depuis quelques années indiquent qu'elle pourrait bien être, au cours du troisième millénaire, un recours thérapeutique prometteur pour le soin de maladies actuellement incurables.

Symboles:

s.m.: substantif masculin

s.f.: substantif féminin

adj.: adjectif

*: signifie que le terme est défini dans le présent glossaire. 
184 Meta, XLVI, 1, 2001

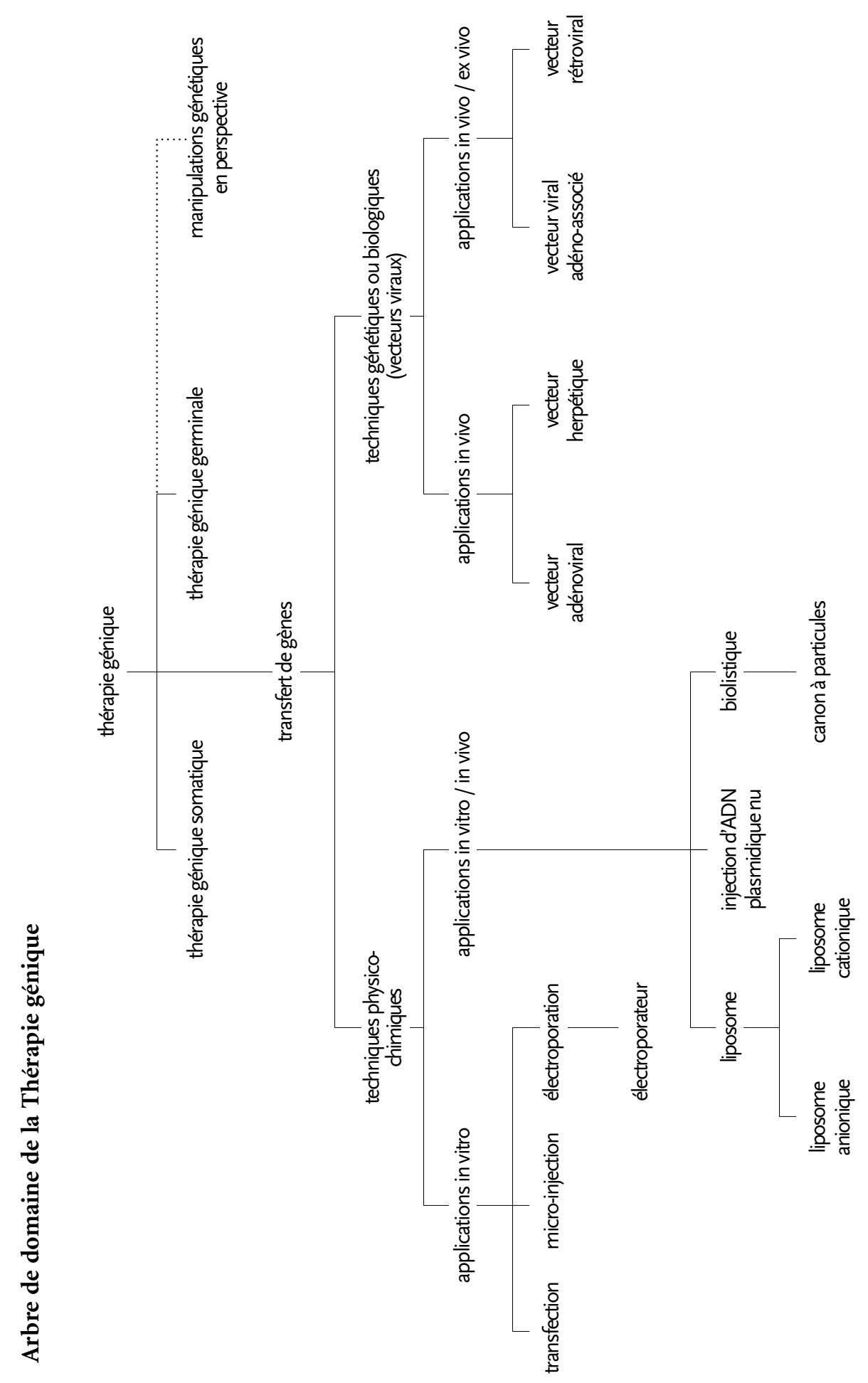


adénovirus (s.m.)

domaine: virologie

définition: Classe de virus à $\mathrm{ADN}$ dépourvus d'enveloppe, comprenant 47 sous-types dont la majorité a une prédilection pour les voies respiratoires et dont la plupart sont non pathogènes pour l'homme.

anglais: adenovirus

biolistique (s.f.)

domaines: génie génétique, thérapie génique

définition: Technique consistant à bombarder des cellules cibles par des micro-projectiles d'or ou de tungstène recouverts d'ADN.

anglais: biolistics, ballistic DNA injection

canon à particules (s.m.)

domaines: génie génétique, thérapie génique

définition: Engin permettant de propulser à grande vitesse des micro-particules enrobées d'ADN codant pour des gènes d'intérêt expérimental ou thérapeutique.

anglais: gene gun, particle gun

électroporateur (s.m.)

domaines: génie génétique, thérapie génique

définition: Appareil servant à faire pénétrer de l'ADN dans des cellules par l'application de fortes impulsions électriques au mélange en suspension.

anglais: electroporator

électroporation (s.f.)

domaines: génie génétique, thérapie génique

définition: Méthode de pénétration d'ADN dans des cellules, basée sur l'utilisation d'impulsions électriques qui augmentent la perméabilité membranaire.

anglais: electroporation

gène suicide (s.m.)

domaines: génétique élémentaire, thérapie génique

définition: Gène codant une protéine qui, directement ou indirectement, est toxique pour la cellule tumorale ou infectée et provoque ainsi sa destruction.

anglais: suicide gene

injection d'ADN plasmidique nu (s.f.)

domaines: génie génétique, thérapie génique

définition: Méthode de transfert de gènes ${ }^{\star}$ consistant à introduire directement dans le tissu cible un plasmide bactérien qui contient le gène à transférer.

anglais: $\quad$ naked plasmid DNA injection

lignée cellulaire de complémentation (s.f.)

domaines: biologie moléculaire, génie génétique

définition: Lignée cellulaire permettant de multiplier des virus défectifs ${ }^{\star}$ servant de vecteurs de gènes*.

remarque: On trouve en français, sous l'influence du terme anglais packaging cell line, les termes lignée de packaging et cellules de packaging. Ces termes sont des calques de structure qu'il faut éviter et remplacer par les termes respectifs lignée d'encapsidation et cellules de complémentation.

anglais: complementing cell line, packaging cell line 


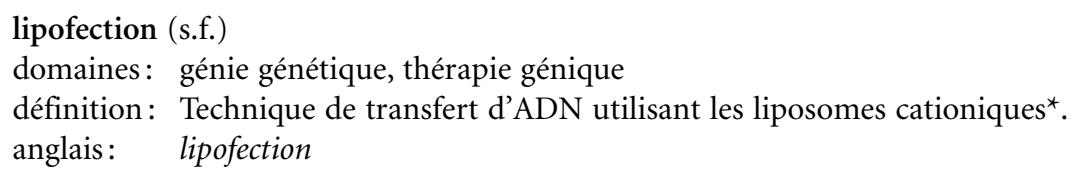
gene, est un type de marqueurs génétiques et ne pourrait traduire de façon systématique le terme anglais genetic marker, car il existe d'autres marqueurs que les gènes.

anglais: genetic marker

micro-injection (s.f.)

domaines: génie génétique, thérapie génique

définition: Technique permettant d'introduire un gène en solution dans une cellule grâce à une micropipette, sous microscope.

anglais: microinjection

oncogène (s.m.)

domaine: oncologie

définition: Gène qui provoque ou favorise l'apparition de tumeurs.

anglais: oncogene

parvovirus (s.m.)

domaine: virologie

définition: Famille de virus, à $\mathrm{ADN}$ monocaténaire encapsidé, doués d'un pouvoir d'oncolyse sélective et d'un pouvoir oncosuppresseur, et se répartissant en virus autonomes et en virus dépendants.

remarque: Les parvovirus humains sont parfois désignés par les auteurs anglo-saxons par le sigle HPV, ce qui peut créer des confusions avec les papillomavirus humains. anglais: parvovirus 
proto-oncogène (s.m.)

domaine: oncologie

définition: Gène existant dans le génome d'une cellule et pouvant devenir oncogène* à la suite d'une activation consécutive à une mutation, une translocation ou à l'insertion d'un promoteur viral actif.

anglais: protooncogene

recombinaison homologue (s.f.)

domaine: génie génétique

définition: Réarrangement génétique intervenant in vitro, entre fragments d'ADN d'origines différentes ou non contigus, ou in vivo, entre copies homologues d'un même gène (remaniement chromosomique), ou par suite de l'intégration dans le génome d'un élément génétique (transposon, prophag ou transgène ${ }^{\star}$ ).

anglais: homologous recombination

rétrovirus (s.m.)

domaine: virologie

définition: Classe de virus à ARN spécifique des Eucaryotes dont la propagation nécessite la conversion de l'ARN en $\mathrm{ADN}$ double brin qui, lui, s'intègre dans le génome de la cellule hôte.

anglais: retrovirus

ribozyme en tête de marteau (s.m.)

domaines: biologie moléculaire, thérapie génique

définition: Molécule d'ARN douée d'activité catalytique et se comportant vis-à-vis des ARN comme une enzyme.

remarque: L'ARN, en plus de son rôle dans le transport de l'information génétique, est capable d'activité catalytique comme le sont les protéines, c'est-à-dire capable d'accélérer des réactions chimiques. Certaines molécules d'ARN peuvent en effet se cliver elles-mêmes ou cliver d'autres molécules d'ARN. C'est pour cette raison qu'on a appelé ces ARN catalytiques des ribozymes, une contraction de ribonucléique et enzyme, autrement dit l'ARN enzymatique.

anglais: hammerhead ribozyme

thérapie génique (s.f.)

domaines: génie génétique, médecine thérapeutique

définition: Ensemble des procédés qui visent à introduire in vitro ou in vivo un gène normal dans des cellules où le même gène, anormal, provoque un déficit fonctionnel à l'origine d'une maladie, ou à introduire un gène codant une protéine ayant une action antitumorale dans les cellules cancéreuses ou antivirale dans des cellules infectées par un virus pathogène.

anglais: gene therapy

thérapie génique germinale (s.f.)

domaine: thérapie génique

définition: Thérapie génique* qui modifie le code génétique des cellules germinales (cellules sexuelles ou gamètes) de l'organisme malade afin de rendre le caractère ajouté un caractère héréditaire de l'espèce.

remarque: Le transfert d'un gène dans les cellules germinales d'un organisme permet la transmission du gène transféré à la descendance de cet organisme; on parle alors de transgénèse* .

anglais: germ-line gene therapy 


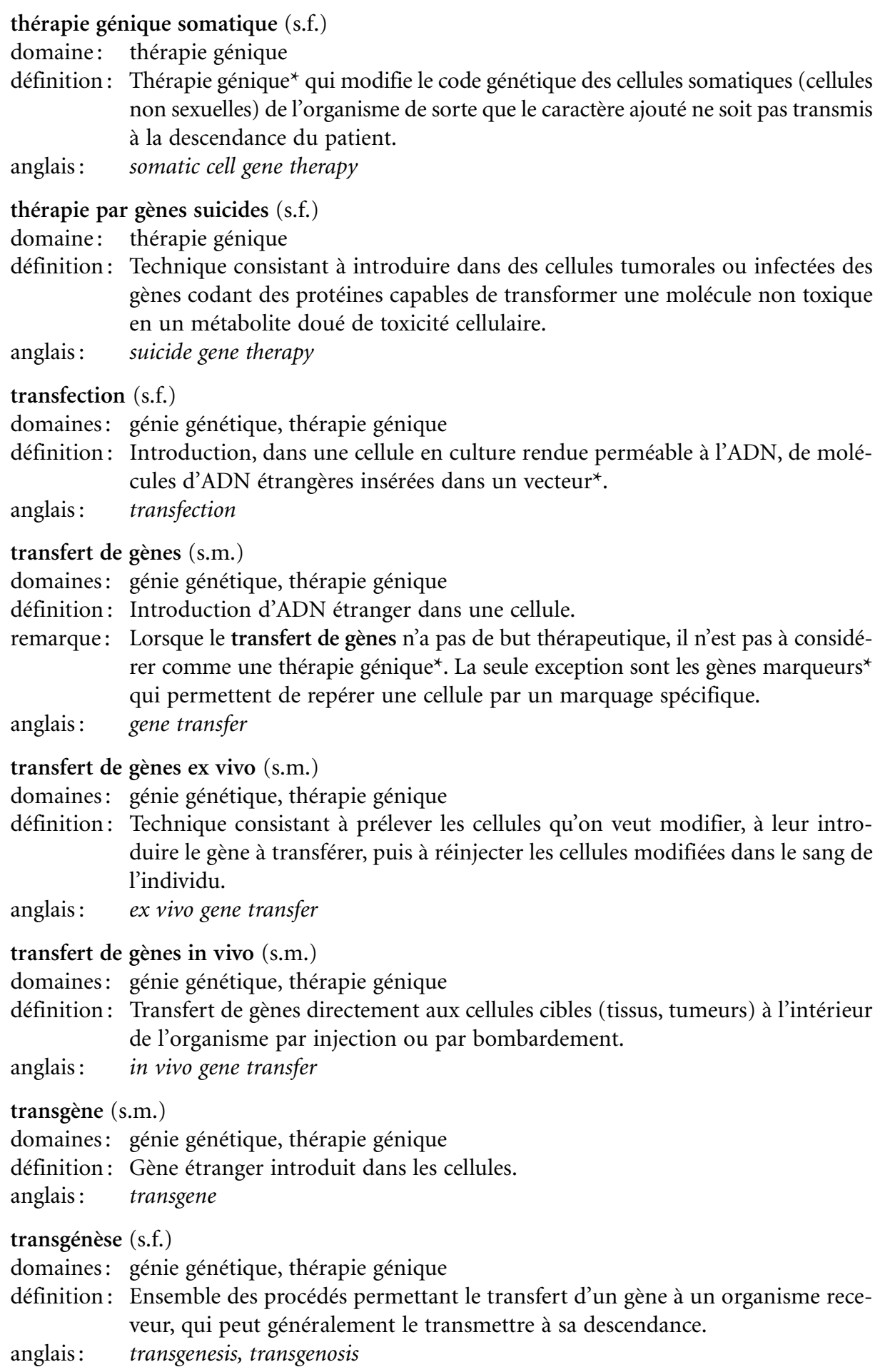




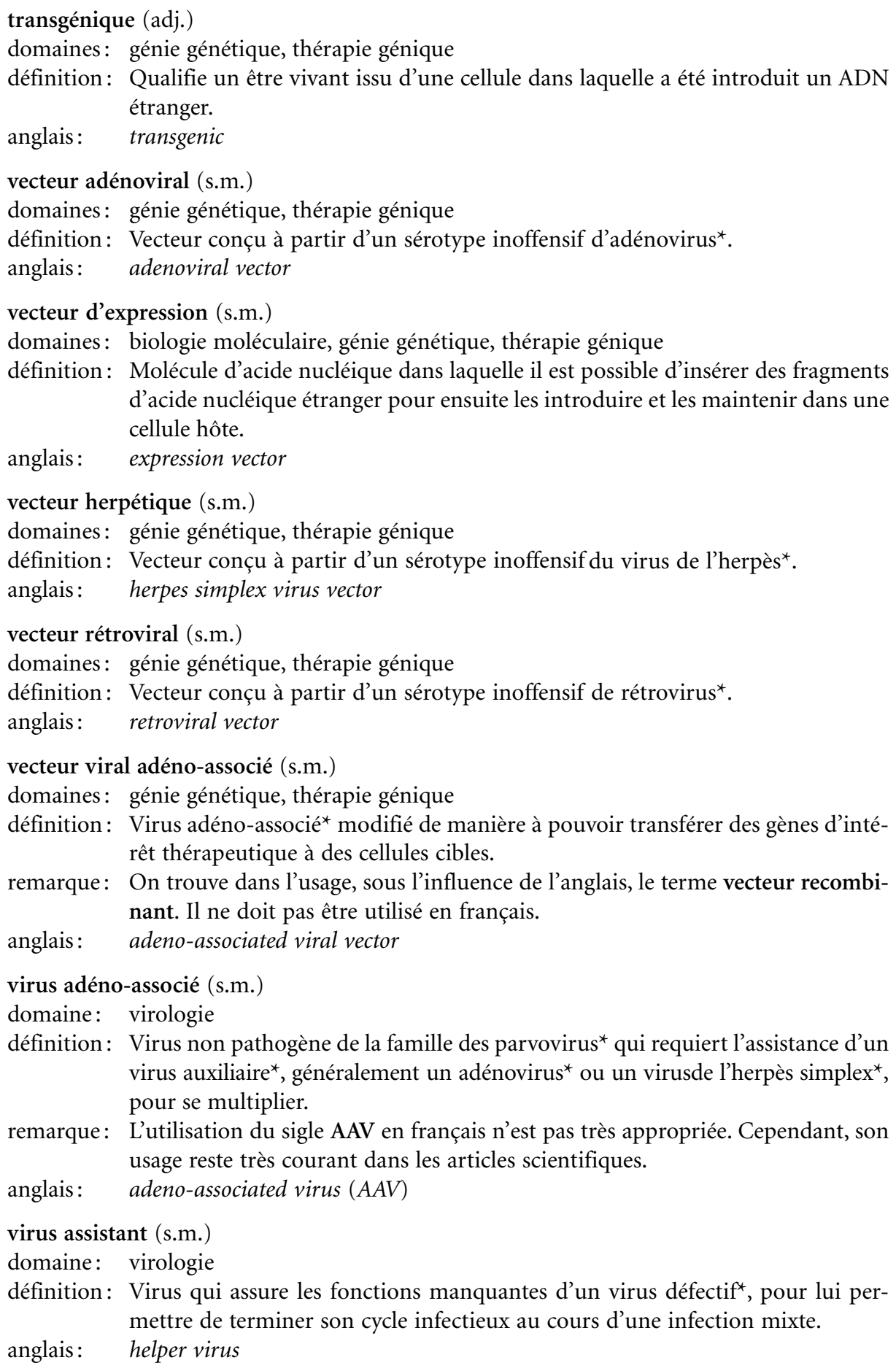
pour se multiplier.

remarque: L'utilisation du sigle AAV en français n'est pas très appropriée. Cependant, son usage reste très courant dans les articles scientifiques.

anglais: adeno-associated virus $(A A V)$

virus assistant (s.m.)

domaine: virologie

définition: Virus qui assure les fonctions manquantes d'un virus défectif*, pour lui permettre de terminer son cycle infectieux au cours d'une infection mixte.

anglais: helper virus 
virus défectif (s.m.)

domaines: virologie, génie génétique, thérapie génique

définition: Virus mutant qui n'est capable de se reproduire après infection qu'en présence d'un virus assistant ${ }^{*}$.

anglais: defective virus

virus de l'herpès simplex (s.m.)

domaine: virologie

définition: Virus à ADN possédant un tropisme pour les cellules nerveuses et pouvant établir une infection latente dans celles-ci.

remarque: Il serait plus approprié de remplacer le sigle HSV par le sigle VHS en français. anglais: herpes simplex virus

\section{Remarques terminologiques et langagières}

1. Il est important de faire une distinction entre les termes thérapie génique et transgénèse. En effet, bien que la transgénèse (trans=transfert + gen=gène) et la thérapie génique soient synonymes d'un point de vue sémantique (ensemble des techniques qui permettent le transfert de gènes à un organisme), elles le sont moins dans l'usage:

a. Actuellement, dans tous les protocoles cliniques, on emploie le terme thérapie génique pour désigner la thérapie génique somatique proprement dite (opération conduisant à l'addition d'un gène dans des cellules non germinales d'un organisme) car, du point de vue éthique, il n'est pas encore admis d'appliquer la thérapie génique germinale à l'humain. Par ailleurs, pour que le terme thérapie génique soit utilisé à bon escient, le transfert de gènes doit nécessairement avoir une visée curative.

b. Quant au terme transgénèse, il est surtout employé dans l'usage pour désigner les manipulations géniques germinales, où le but du transfert de gènes serait la transmission du transgène à la descendance du receveur, sans qu'il y ait pour autant une anomalie à traiter.

2. Le transfert de gènes et la thérapie génique sont deux notions apparentées si bien que l'usage a tendance quelquefois à négliger les différences sémantiques entre les deux termes.

Ce qu'il faut retenir sur la thérapie génique:

- c'est un processus (ensemble de procédés) à visée thérapeutique curative;

- c'est un concept mis en application par les techniques du génie génétique.

Par contre, ce qu'il faut savoir sur le transfert de gènes:

- c'est une opération qui consiste à introduire un gène cloné dans une cellule receveuse en suivant diverses étapes:

a. la préparation du gène,

b. l'intégration du gène dans un vecteur d'expression;

c. le transfert proprement dit à la cellule receveuse.

- sa finalité n'est pas nécessairement thérapeutique.

On en déduit que:

- la thérapie génique a une plus grande portée sémantique que le transfert de gènes. Lorsque ce dernier est effectué dans un but curatif, il s'inscrit dans le processus de la thérapie génique et il en constitue l'étape la plus importante, si bien que, dans l'usage, on a tendance à assimiler la thérapie génique au transfert de gènes proprement dit (transfert de gènes $\varnothing$ thérapeutique $=$ thérapie génique). Ainsi, la relation des deux termes est une relation de tout à partie. 
- le point de vue qui situe la thérapie génique à un niveau d'abstraction plus élevé que celui du transfert de gènes n'est pourtant pas à exclure, puisque le concept théorique de la thérapie génique est mis en application dans la pratique par le transfert de gènes, ce qui confère aux deux termes une relation de synonymie, mais à différents niveaux d'abstraction. 